\title{
Worth making a song and dance about database right?
}

\section{Ewan Nettleton}

is a senior associate solicitor in the Intellectual Property Department at Bristows. He specialises in Intellectual Property Law, with an emphasis on litigation. He has an MA in Chemistry and a DPhil in Protein Chemistry, and is particularly interested in matters relating to the IT and life sciences industries.

\section{Tom Ohta}

is a trainee at Bristows, who will qualify shortly as an associate in the Commercial Disputes Department. He has a BA in Modern History, and is particularly interested in matters affecting the technology, media and telecommunications sector and the consumer products industries.

ABSTRACT Database right has trodden an unsteady course since it was created over a decade ago. Many practitioners wrote off this relatively fledgling intellectual property right following the European Court of Justice's (ECJ) ruling in the British Horseracing Board (BHB) and Fixtures Marketing cases, which seemed to severely curtail the protection it affords. However, the more recent ruling from the ECJ in the Directmedia case reinvigorated interest in the right, confirming that the acts that can infringe it are broad. Hot on the heels of Directmedia comes the most recent ECJ decision on database right, Apis v. Lakorda, a referral from the national courts of recent EU entrant, Bulgaria. This article considers where Bulgaria's first intellectual property referral to the ECJ leaves database owners.

Journal of Database Marketing \& Customer Strategy Management (2009) 16, 221-225.

doi:10.1057/dbm.2009.19

Keywords: database right; extraction; substantial; Apis; Lakorda

Correspondence: Ewan Nettleton Bristows, 100 Victoria Embankment, London, EC4Y ODH, UK E-mail: ewan.nettleton@ bristows.com

\section{INTRODUCTION}

Database right was created over a decade ago with the aim of protecting the substantial investment made in obtaining, verifying or presenting the contents of a 'database', defined as a collection of independent works, data or other materials arranged in a systematic or methodical way, and individually accessible by electronic or other means.

Since the BHB and Fixtures Marketing cases, substantive case law on database right has been sparse. However, last
October, the ECJ provided guidance on the scope of the acts that infringe the right in its ruling in Directmedia. ${ }^{1}$ There, the ECJ adopted a broad interpretation of the infringing act of extraction,,$^{2}$ rejecting the contention that only acts consisting of mechanical reproduction, without adaptation, such as merely copy and pasting, could fall within the definition. The Court held that transfer of data following an on-screen consultation and an individual assessment of a database's content could fall within 'extraction'. ${ }^{3}$ 


\section{APIS-HRISTOVICH EOOD v. LAKORDA AD}

\section{Setting the scene}

The most recent, substantive database right case is Apis v. Lakorda. ${ }^{4}$ It is one of the first intellectual property rulings to be referred to the ECJ from Bulgaria.

Apis is a Bulgarian software company that developed and marketed a legal database, comprised of two modules: (1) a legislation module and (2) a case law module. These were marketed as separate products, and are the sort of databases lawyers use to check legal points on which they are advising their clients and to conduct legal research. Some of Apis' employees left its software department and founded a rival company, Lakorda, which subsequently began to market its own legal database that also included a legislation module and case law module. Apis claimed that its former employees had unlawfully extracted substantial parts of the contents of its database, enabling Lakorda to produce and market its own competing database with the same two modules.

The Bulgarian court referred a number of somewhat disparate questions to the ECJ. Before answering a referral from a national court, the ECJ will usually avail itself of a non-binding opinion from an Advocate General who gives his/her view on the law and on how the questions should be answered. Unusually, the ECJ decided not to seek input from an Advocate General here. Exactly why the Advocate General's guidance was not sought is unclear. Some commentators have quipped that it was either because the referred questions were (1) so easy that the ECJ felt it needed no guidance or (2) so complex that the ECJ feared that an Advocate General's opinion would only serve to muddy the water further. We shall leave it to the readers to reach their own conclusions, but another possibility is simply that having considered similar issues relatively recently in Directmedia, the ECJ felt it was able to press ahead and decide the case without guidance.

Of the various issues considered by the Court, those likely to be of most interest to database marketers are summarised below, concentrating on the Court's assessment of the meaning of the infringing act of extraction and on its assessment of the 'substantial part' threshold of the data that need to be affected for infringement to have taken place.

\section{'Extraction'}

Where a database qualifies for protection, database right gives its maker the right to prevent extraction of the whole or a substantial part of its contents evaluated quantitatively and/or qualitatively. Extraction is defined as the permanent or temporary transfer of all or a substantial part of the contents of a database to another medium by any means or in any form.

In Apis v. Lakorda, the Bulgarian court sought guidance from the ECJ on a number of points in relation to the criteria that should be taken into account when determining whether an extraction has taken place. These can be summarised as follows:

1. How important is the objective pursued by the person transferring the data from the protected database? Does it matter that the transfer was for the purpose of creating another competing database?

The ECJ confirmed that the objective pursued by the act of transfer of the data is irrelevant when determining whether there has been an infringing extraction. This is in keeping with its decision in Directmedia. Notably, however, the Court suggested that the objective could, in certain circumstances, be relevant to assessing the extent of the damage suffered by the database owner. For instance, if the purpose of the unlawful extraction was to set up and market a new, competing 
database, this could be taken into account. It was a matter for the national court to ascertain whether such an objective existed.

\section{If the contents of the protected database} are transferred to another medium, resulting in the content of the relevant material being modified in some form, or being organised in a different structure, does this mean that extraction has not taken place? What significance, if any, should be placed upon any such differences in structure or content between the opposing databases?

Building on its decision in Directmedia, the ECJ considered that the fact that all, or part, of the contents of a protected database are found in a modified form in another database does not, in itself, preclude a finding that extraction has taken place. Similarly, the Court held that it is irrelevant that the contents are structurally organised in a different manner in the allegedly infringing database.

\section{'Substantial part'}

As noted above, a substantial part of a protected database must have been extracted or re-utilised, evaluated either quantitatively and/or qualitatively, in order for an infringement to have occurred. The ECJ was asked about what was involved in the quantitative and qualitative assessments.

Quantitative evaluation One of the questions the ECJ had to consider raised the issue of how the quantitative evaluation is to be carried out where a database is made up of sub-groups, such as modules, which are in themselves independent commercial products. In the case itself, Apis' legal database comprised a case law module and a legislation module, with each module subject to separate product licences. Apis claimed that Lakorda had extracted and re-utilised texts from approximately 82 per cent of its legislation module, which it alleged Lakorda had then used to make its own legislation module. This raised the question as to whether the court should assess whether a substantial part of Apis' protected database had been extracted or re-utilised in relation to the entire commercial product, that is, Apis' legal database as a whole, or in relation to the relevant sub-group, Apis' legislation module.

The ECJ stated that where a database consists of several separate modules, the first step is to determine whether the particular module in question constitutes a database that is eligible for database right protection in and of itself. For it to do so, there has to have been a sufficiently substantial investment in obtaining, verifying or presenting the contents of the particular module, such that it can benefit from database right. This could be more of an issue for database owners who create their own data because, following the restrictive approach in BHB and Fixtures Marketing, resources used for the creation of the data or in verifying the data at the point of creation may not count towards this assessment.

If there has been sufficient investment, such that the module can itself be protected by database right, the ECJ stated that the quantitative evaluation of whether a substantial part has been extracted or re-utilised should be made against the relevant module - that is, whether the data extracted or re-utilised amount to a substantial part of the particular module affected. However, if the module does not amount to a protected database in and of itself, the comparison is made against the database as a whole.

By adopting this approach, the ECJ reaffirmed the position taken in the $B H B$ and Fixtures Marketing cases that the concept of a substantial part of the contents of a protected database, evaluated quantitatively, refers to the volume of materials extracted or re-utilised in relation to the contents of the database. It is notable that the ECJ held that modules could in certain 
circumstances be considered individually, making it more likely that the amount of data affected will be deemed substantial on a quantitative assessment than if the database were considered as a whole. However, the ECJ also stated that the fact that a module within a wider database is marketed separately as an independent product was a commercial arrangement that did not in itself make the database eligible for database right protection.

Database owners and commentators have previously speculated about whether databases should perhaps be split up to enhance the database right owner's protection. The Apis ruling shows that there is some scope for this, but it also demonstrates that care must be exercised to ensure that the component modules individually qualify for protection in their own right.

It is also noteworthy that the size of the database into which the extracted or re-utilised material is transferred does not matter. If, for example, the extracted or re-utilised material made up only 10 per cent of the original database, but amounted to 95 per cent of the allegedly infringing one, the high percentage of data from the original database in the new database would be irrelevant, as the quantitative assessment concerns only whether a substantial part of the original database has been used, and that percentage would be low.

Qualitative evaluation In relation to the qualitative assessment, Apis brought to the court's attention the fact that, as part of its case law module, it had collected together 2516 unpublished judicial decisions by obtaining permission from the relevant courts. Apis argued that the court should take the value of the unpublished case law into account when making the qualitative assessment.

When evaluating the concept of a substantial part in qualitative terms, the ECJ's view was that the key consideration was the scale of the investment in the obtaining, verification or presentation of the contents in question. It stressed that the qualitative evaluation was not affected by the issue of whether the contents in question amount to a quantitatively substantial part of the contents of the protected database. The Court noted that it was possible that a quantitatively negligible part of the contents of a protected database could in fact amount to a substantial part in qualitative terms if there had been significant human, technical or financial investment in obtaining that quantitatively negligible part.

However, the ECJ made clear that the investment made in obtaining the relevant data should not be confused with the intrinsic value of the materials affected by the act of extraction. Reaffirming its findings in the BHB and Fixtures Marketing cases, the Court made clear that the intrinsic value of the data affected was not a relevant criterion. Database owners are still therefore vulnerable to third parties cherry picking the most relevant or up-to-date information in their databases, and such acts are unlikely to infringe unless they are carried out in a repeated and systematic fashion that amounts to a substantial part overall. The position for database right therefore contrasts with the position under copyright law, in which the value or importance of the part in question may be a relevant factor.

\section{Publicly available documents}

The ECJ also considered the implications of the data in a database being public and widely accessible from other sources. This issue was referred to in the context of Apis' legislation module, as its legislative content was of an official and publicly accessible nature. The ECJ confirmed that just because data are of an official and publicly accessible nature does not relieve the court of its obligation to assess whether a substantial investment had been made in 
obtaining, verifying or presenting them. The court must still carry out the substantial investment analysis both quantitatively and qualitatively to determine whether such databases are protected.

\section{CONCLUSIONS}

In answering the questions referred in the Apis case, the ECJ has reaffirmed the broad interpretation of the infringing act of extraction it adopted in Directmedia. Helpfully, it has also provided guidance on various factors that are relevant when determining whether infringement has taken place.

So where does this leave database marketers and other owners of database right? The ruling does confirm certain aspects of the restrictive approach taken in the BHB and Fixtures Marketing cases, limiting the protection the right affords. Most importantly, Apis confirms that the Court's main concern when considering whether a substantial part of a database has been affected by an alleged infringement is with the investment made in obtaining, verifying and/or presenting the data in the part affected. It will not look at the intrinsic economic value of the information. Cherry picking of the most relevant or up-to-date information in a protected database is therefore unlikely to infringe unless it is carried out in a repeated and systematic fashion such that over time the part affected is substantial overall. Though not considered in Apis, it also remains the case that much of the investment made by database-makers who create their own data may not count towards the investment required for database right to subsist.

That said, the Apis ruling undoubtedly contains some encouragement for database owners. The ECJ has taken a very wide view of the acts that infringe database right, with extraction including any unauthorised act of appropriation of a database's contents in part or in whole, irrespective of the nature and form of the process involved. Thus, the transfer of the whole or a substantial part of a database to another medium, even temporarily, can be sufficient to establish infringement. Furthermore, infringement can be found regardless of whether the extracted or re-utilised data have been modified in content or organised differently in the new database.

Another point of interest arising from the case is the Court's commentary on the alleged infringer's objective in using the data. In addition to confirming that the alleged infringer's objective is irrelevant when assessing whether there has been infringement by extraction, the ECJ confirmed that it may nonetheless be taken into account when assessing the extent of the damage caused to the original database maker. Thus, the unauthorised extraction or re-utilisation of data for damaging purposes such as creation of a competing database may improve a database owner's case for damages against the infringer.

Overall therefore, although there remain some significant limitations on database right protection, most database owners will see the Apis decision as a positive step forward.

\section{REFERENCES AND NOTES}

1 Directmedia Publishing GmbH v. Albert-LudwigsUniversität Freiburg (Case C-304/07, 9 October 2008).

2 One of the two acts which can infringe database right, the other being 're-utilisation' (making data from the database available to the public).

3 For further background, see Nettleton, E. (2009) Poetic justice for owners of database right. Journal of Database Marketing and Customer Strategy Management 16(1): 57-60.

4 Case C-545/07, 5 March 2009. 